\title{
Manufacture and characterization of kefir made from cow and buffalo milk, using kefir grain and starter culture
}

\author{
O. Gul, ${ }^{* 1}$ M. Mortas, $\dagger$ I. Atalar, $\dagger$ M. Dervisoglu, $\dagger$ and T. Kahyaogluł \\ ${ }^{*}$ Program of Food Technology, Yeşilyurt Demir-Celik Vocational School, Ondokuz Mayis University, Samsun, Turkey 55330 \\ †Food Engineering Department, Engineering Faculty, Ondokuz Mayis University, Samsun, Turkey 55139 \\ ‡Department of Food Engineering, Faculty of Chemical and Metallurgical Engineering, Yildiz Technical University, Istanbul, Turkey 34220
}

\section{ABSTRACT}

The microbiological and chemical characteristics as well as organic and amino acid profiles of kefir samples made from cow and buffalo milks fermented by kefir grains and starter culture were investigated during storage for $21 \mathrm{~d}$ at $4^{\circ} \mathrm{C}$. After incubation, lactic, acetic, and citric acid concentrations showed a difference among the samples due to milk type and production methods. Storage time had little effect on the organic acid values of kefir samples. As compared with cow milk kefir, buffalo milk kefir had higher numbers of microorganisms, except lactobacilli, at the end of storage. Whereas $\mathrm{pH}$ and titratable acidity exhibited similar changes during storage in all kefir samples, ethanol levels were significantly increased in buffalo milk kefir samples. Glutamic acid was the major amino acid at all sampling times for all samples. Tyrosine, serine, histidine, alanine, methionine, and lysine concentrations were determined to be different in all samples depending on milk type. In general, due to the higher microbial population (especially yeast), kefir made from buffalo milk may be preferred. Key words: buffalo milk, cow milk, kefir, characterization

\section{INTRODUCTION}

Kefir is a fermented dairy product originating from the Caucasus Mountains (Gronnevik et al., 2011). In traditional kefir production, milk is fermented with a starter culture of small, irregularly shaped, and gelatinous yellowish grains (Guzel-Seydim et al., 2000a). Kefir has a slightly sour, acidic taste and is creamy in consistency. It has become a popular drink in many parts of the world, from Japan to eastern and northern Europe (Otles and Cagindi, 2003). Its popularity is mainly based on its nutritive content and health benefits. Kefir has numerous benefits to human health, such as improving lactose digestion and tolerance in adults

Received August 19, 2014.

Accepted November 25, 2014.

${ }^{1}$ Corresponding author: osman.gul@omu.edu.tr as well as antimicrobial, antitumoral, antioxidant, antimutagenic, and antiapoptotic effects (Hertzler and Clancy, 2003; Güven et al., 2003; Matsuu et al., 2003; Liu et al., 2005; de Moreno de LeBlanc et al., 2006; Lopitz-Otsoa et al., 2006).

Kefir is generally consumed with meals and alone as a probiotic drink. It is recommended for consumption because of its probiotic bacteria and yeast mixture (Simova et al., 2002). Kefir's probiotic property comes from kefir grains or cultures containing various species of lactobacilli, lactococci, Leuconostoc spp., acetic acid bacteria, and yeasts, among others (Wszolek et al., 2001; Witthuhn et al., 2005). The microflora of kefir and kefir grains differs according to their origin and production methods (Temmerman et al., 2004).

The kefir-producing process is divided 2 categories: traditional and industrial methods (Otles and Cagindi, 2003). The main difference between the 2 techniques is the inoculation of kefir grain or culture into milk. Kefir grains are mostly used for traditional kefir production. Due to variable microflora in the kefir grains, sensory properties of kefir samples can show differences depending on the origin of the grains and conditions of storage and handling. For standard production, industrial brands use kefir starter cultures that involve pure kefir microflora strains (Petersson et al., 1985; García Fontán et al., 2006).

Kefir is made from different milks, such as bovine, goat, and ovine (Wszolek et al., 2001). In addition, ewe (Farnworth, 2006), soy (McCue and Shetty, 2005), coconut, and rice milk (Otles and Cagindi, 2003) can be used for producing kefir. Choice of culture and milk type is important for kefir characteristics. In addition, differences between kefir samples produced from various types of milks and cultures have been studied by some researchers. Wszolek et al. (2001) investigated properties of kefir samples produced using 3 types of cultures and bovine, goat, or ovine milk. In another study, the effects on milk type and starter culture on kefir characteristics were reported (Oner et al., 2010).

Buffalo milk differs from other milks not only in terms of its taste, but also in chemical composition 
(Phill, 2005). It has higher calcium and protein and less cholesterol content than cow milk. Moreover, tocopherol level and peroxidase activity of buffalo milk are 2 and 4 times higher, respectively, compared with cow milk (Phill, 2005). Buffalo milk can be considered as a favorable raw material for the production of dairy products based on its fat and protein content. Although some dairy products, such as mozzarella and paneer cheese, buffalo yogurt, and so on, are produced using buffalo milk worldwide, to the best of knowledge no research has been focused on use of buffalo milk as a raw material in kefir production. Therefore, the objective of the current research was to investigate and compare chemical and microbiological characteristics of kefir samples manufactured with cow and buffalo milks using kefir grains or commercial kefir culture.

\section{MATERIALS AND METHODS}

\section{Materials}

The raw cow $(2.6 \mathrm{~g} / 100 \mathrm{~g}$ of fat, $11.7 \mathrm{~g} / 100 \mathrm{~g}$ of TS, and $6.68 \mathrm{pH})$ and buffalo milk $(4.9 \mathrm{~g} / 100 \mathrm{~g}$ of fat, 17.5 $\mathrm{g} / 100 \mathrm{~g}$ of TS, and $6.94 \mathrm{pH}$ ) were supplemented at the Pilot Dairy Plant (Ondokuz Mayıs University) and a local farm in Samsun, Turkey, respectively. The TS contents of raw cow and buffalo milk were standardized to $11.5 \mathrm{~g} / 100 \mathrm{~g}$ by adding drinking water. Kefir grains and direct vat inoculation starter culture were obtained from Pilot Dairy Plant and Danisco Biolacta (Kefir DC1 1,000 L, Danisco Biolacta, Olsztyn, Poland), respectively.

\section{Kefir Manufacture}

Raw buffalo and cow milks were pasteurized at $90^{\circ} \mathrm{C}$ for $15 \mathrm{~min}$ after the standardization. The pasteurized milks were cooled down to $25^{\circ} \mathrm{C}$ using water circulation by a heat exchanger. To obtain kefir made using kefir grains, cooled milks were inoculated with $5 \%$ (wt/vol) kefir grains rate and incubated at $24^{\circ} \mathrm{C}$ for $18 \mathrm{~h}$. At the end of the incubation, kefir grains were separated via a sieve and then the kefir samples were taken into high-density polyethylene bottles.

The procedure for making kefir with kefir starter culture involves different steps. Freeze-dried kefir starter culture was added to raw milks at a level of $0.025 \mathrm{~g} / \mathrm{L}$ of milk. According to the supplier, the starter culture contains Lactococcus spp., Leuconostoc spp., Streptococcus thermophilus, Lactobacillus spp., and kefir yeast. After inoculation, all milk samples were incubated at $24^{\circ} \mathrm{C}$ for $18 \mathrm{~h}$ and kefir samples were taken into highdensity polyethylene bottles.
All kefir products were stored for $21 \mathrm{~d}$ at $4^{\circ} \mathrm{C}$ and analyzed at d 1 (after the incubation), 7, 14, and 21 for all analyses. Cow (C) and buffalo (B) milk kefir made using kefir grains $(\mathbf{K G})$ and starter culture $(\mathbf{K S})$ were named KG-C, KG-B, KS-C, and KS-B, respectively.

\section{Enumeration of Microorganisms}

Kefir samples $(10 \mathrm{~mL})$ were dispersed with $90 \mathrm{~mL}$ of sterile sodium thiosulfate solution $(0.2 \% \mathrm{wt} / \mathrm{vol})$ and homogenized for 1 min using a stomacher (Smasher, AES Chemunex, Bruz, France). Further dilutions were made using Ringer solution (Merck, Darmstadt, Germany). Lactobacilli counts were determined on de Man Rogosa Sharpe agar (Merck) after incubation at $30^{\circ} \mathrm{C}$ under anaerobic conditions for 5 d (García Fontán et al., 2006). Lactococci counts were enumerated on M17 Agar (Merck) at $30^{\circ} \mathrm{C}$ for $3 \mathrm{~d}$ (Irigoyen et al., 2005). Leuconostoc spp. counts were determined on de Man Rogosa Sharpe Agar (Merck) incorporated with vancomycin hydrochloride (Sigma-Aldrich, St Louis, MO) at $30^{\circ} \mathrm{C}$ for $3 \mathrm{~d}$ (García Fontán et al., 2006) and yeasts were grown on yeast extract glucose chloramphenicol agar (Merck) at $25^{\circ} \mathrm{C}$ for $3 \mathrm{~d}$ (Magra et al., 2012).

\section{Proximate Analyses}

The titratable acidity of kefir samples was determined using the AOAC titration method using 0.1 $N \mathrm{NaOH}$ (AOAC International, 1992). The $\mathrm{pH}$ was measured at $15^{\circ} \mathrm{C}$ using a calibrated $\mathrm{pH}$ meter (Eutech Cyberscan pH 2700, Ayer Rajah Crescent, Singapore) by directly submerging the probe into the homogenized kefir sample. Total solid contents of the kefir samples were determined gravimetrically using an oven at $103^{\circ} \mathrm{C}$ until a constant weight was obtained (approximately $2.5 \mathrm{~h})$.

\section{Ethanol Content}

The ethanol content in kefir samples was determined following the method of Erbas (2003) with some modifications. A sample of approximately $2.5 \mathrm{~g}$ of kefir was diluted in $20 \mathrm{~mL}$ of deionized water and centrifuged at $3,200 \times g$ for $30 \mathrm{~min}$ at $25^{\circ} \mathrm{C}$. The supernatant was collected and filtered using Whatman 42 filter paper (Whatman International, Maidstone, UK) and then kept in the deep freeze until analysis. After thawing, the samples were filtered on a $0.45-\mu \mathrm{m}$ membrane filter and injected on a gas chromatograph (Shimadzu GC MS-QP2010 Plus, Kyoto, Japan) equipped with ZBWAX polyethylene glycol colon $(30 \mathrm{~mm} \times 25 \mathrm{~mm} \times$ $0.25 \mu \mathrm{m}, 7 \mathrm{HG}-\mathrm{G} 007-17)$. Operating conditions were 
set as flame-ionization detector and injector at $200^{\circ} \mathrm{C}$, oven temperature increased from 70 to $120^{\circ} \mathrm{C}$ by $4^{\circ} \mathrm{C}$ per minute, injection volume of $1 \mu \mathrm{L}$, and carrier gas of nitrogen at $100 \mathrm{kPa}$. The calibration curve of ethanol obtained 5 different concentrations ( 0.1 to $50 \mu \mathrm{L} / \mathrm{L})$ of ethanol standard solution ( $>99.9 \%$, Sigma-Aldrich), which was used for the quantification of ethanol contents of kefir samples.

\section{Organic Acid Composition}

Organic acids were determined by HPLC according to Laye et al. (1993) and Fernandez-Garcia and McGregor (1994) with some modifications. Five milliliters of homogenized kefir samples was added to $25 \mathrm{~mL}$ of $0.01 \mathrm{~N} \mathrm{H}_{2} \mathrm{SO}_{4}$, vortexed for $1 \mathrm{~min}$, and then centrifuged (Sigma 3K30, Germany) at 7,000 $\times g$ at $4^{\circ} \mathrm{C}$ for $7 \mathrm{~min}$. The resulting supernatants were passed through a syringe filter (pore size $=45 \mu \mathrm{m}$; Chromafil GF/ PET-45/25, Macherey-Nagel AG, Duren, Germany). Filtered samples were injected into a Shimadzu HPLC system equipped with a pump (Shimadzu LC-20AT), photodiode array detector (Shimadzu SPD-M20A), column oven (Shimadzu CTO-10AS VP) set at $65^{\circ} \mathrm{C}$, auto sampler (Shimadzu SIL-10A), and data station (Shimadzu CBM-20A). The analyses were carried out at a flow rate $0.7 \mathrm{~mL} / \mathrm{min}$ with a Shim-Pack column $(150 \times 4.6 \mathrm{~mm}, 4 \mu \mathrm{m}$; Tokyo, Japan $)$ using $10 \mathrm{mM}$ $\mathrm{H}_{2} \mathrm{SO}_{4}$ as the mobile phase. Organic acids were defined using external standards (lactic, acetic, citric and butyric acids; Sigma-Aldrich). The quantification of the results was performed depending on standard curves of individual organic acids covering the concentration range of 10 to $500 \mathrm{~mL} / \mathrm{L}$.

\section{AA Composition}

A modification of the methods of Fenelon et al. (2000) and Paramas et al. (2006) was used for extraction and measurement of the concentrations of AA in the kefir samples. Ten milliliters of the kefir samples were mixed with $24 \%$ trichloroacetic acid at 1:1 vol/vol and held for $10 \mathrm{~min}$. Than the mixture was centrifuged (Sigma $3 \mathrm{~K} 30$, Steinheim, Germany) at $14,400 \times g$ at $20^{\circ} \mathrm{C}$ for 10 min. Supernatant was collected by pipette, diluted with $0.4 M$ borate buffer at $\mathrm{pH} 10.5$, and filtered using a $0.45-\mu \mathrm{m}$ nylon disc filter (Chromafil GF/PET-45/25, Macherey-Nagel AG). The filtrate was diluted with $o$-phthalaldehyde for derivatization during $3 \mathrm{~min}$ and then $20 \mu \mathrm{L}$ of dilution was injected into a reverse-phase HPLC system to detect and quantify the AA. The HPLC system (Shimadzu) consisted of a DGU-20A5 degasser, LC-20AT pump, CBM-20A data station, CTO-10AS VP column oven, SIL-20A auto sampler, and a RF-
10AXL fluorescence detector. Separation of AA was performed with a reverse-phase Nova-Pack C18 column $(150 \times 3.9 \mathrm{~mm}, 4 \mu \mathrm{m})$ from Waters (Milford, MA). The mobile phase A was $10 \mathrm{~m} M$ sodium phosphate buffer (pH 7.3):methanol:tetrahydrofuran (80:90:1, vol/vol/ vol) and mobile phase B was $10 \mathrm{~m} M$ sodium phosphate buffer ( $\mathrm{pH} 7.3)$ :methanol (20:80, vol/vol) with a flow rate $1.5 \mathrm{~mL} / \mathrm{min}$ under gradient elution conditions: $100 \%$ A during $0.5 \mathrm{~min}, 0$ to $15 \%$ of $\mathrm{B}$ in $\mathrm{A}$ for $6 \mathrm{~min}$, $15 \%$ B isocratically for $5 \mathrm{~min}, 15$ to $30 \%$ of B for 5 min, 30 to $40 \%$ of B for $4 \mathrm{~min}$, and 40 to $80 \%$ of B for $12 \mathrm{~min}$. The AA were detected at the excitation and emission wavelengths of 340 and $426 \mathrm{~nm}$, respectively. The AA standard (AA-S-18, Sigma-Aldrich) solutions (10-200 mmol) were diluted with $0.4 M$ borate buffer to be used for quantification.

\section{Statistical Analysis}

The production and storage of kefir samples made from cow and buffalo milks fermented by kefir grains and starter culture were performed in triplicate and all analyses were performed in duplicate. An ANOVA was performed by the General Linear Models using SPSS 17.0 package program (SPSS Inc., Chicago, IL), and Tukey test was used to find significant differences $(P<$ 0.05) among the kefir samples and storage time.

\section{RESULTS AND DISCUSSION}

\section{Microbial Profile}

Kefir samples were analyzed for their microbiological properties at d 1 (after the incubation), 7, 14, and 21 of storage at $4^{\circ} \mathrm{C}$. The counts of lactobacilli, lactococci, Leuconostoc spp., and yeast in all samples were determined. Figure 1A shows the mean changes in the yeast counts of 4 different kefir samples. The highest yeast counts were determined in KG-B kefir sample $(P$ $<0.05)$ after incubation. Yeast counts increased significantly $(P<0.05)$ until $14 \mathrm{~d}$ of storage except for KG-C. After this period, except for KS-B, yeast counts in all kefir samples declined. Similar to our results, a slight decrease of yeast counts between d 14 and 21 of the storage was also observed by Irigoyen et al. (2005). The decrease of the yeast counts after d 14 could be dependent on the increase of the lactobacilli counts. The counts of yeast in kefir samples were affected by some acids producing lactic acid bacteria by the transformation of pyruvic acid (Simova et al., 2002). At the end of incubation, when yeast counts in the KS-C sample $(2.99 \mathrm{log} / \mathrm{cfu})$ were found to be higher that of KS-B sample $(2.04 \log \mathrm{cfu} / \mathrm{mL} ; P<0.05)$, there was no significant difference between the yeast counts of 


\section{$\nabla$ KG-C $\odot$ KG-B \\ * KS-C $\quad$ - KS-B}
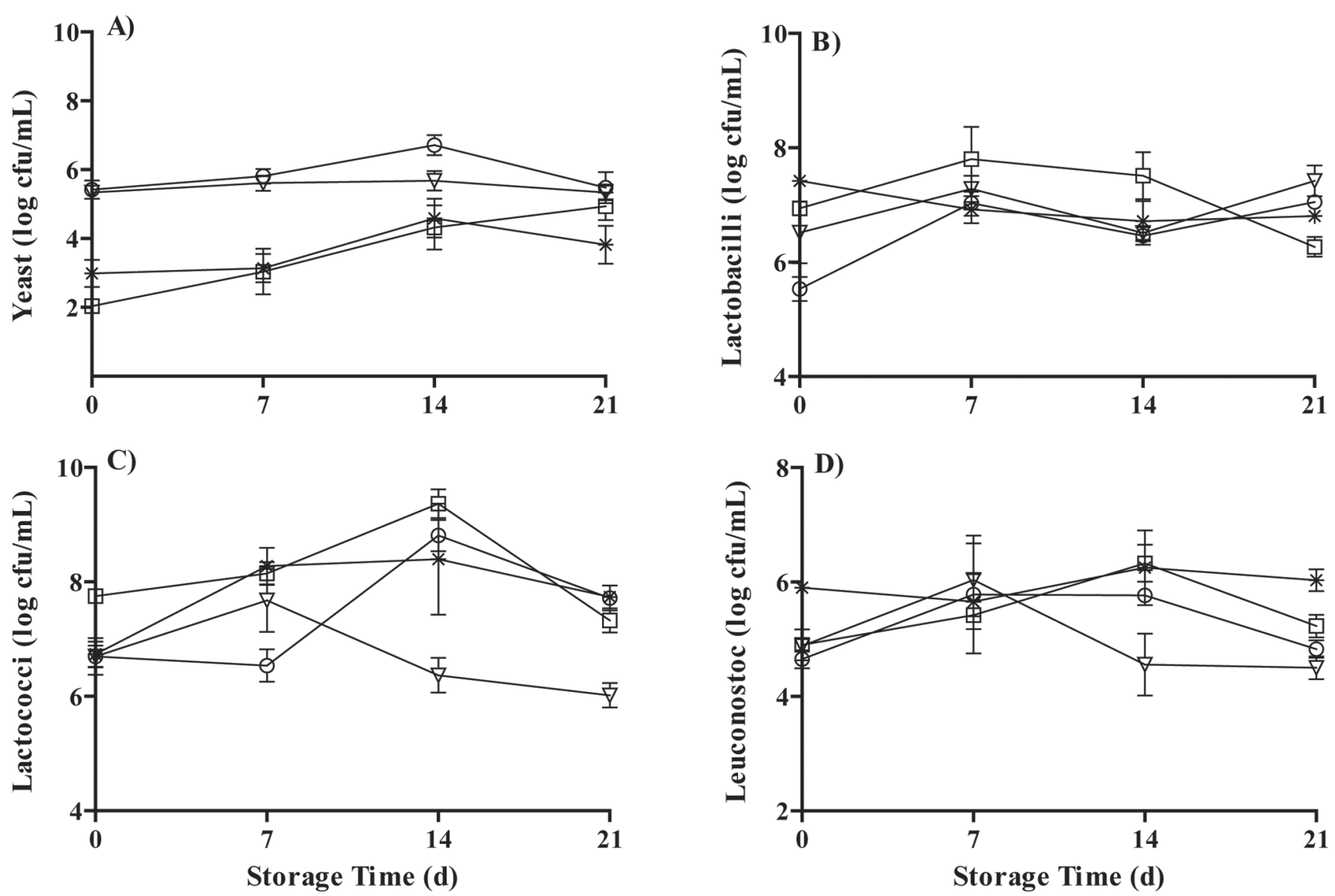

Figure 1. The change of yeast (A), lactobacilli (B), lactococci (C), and Leuconostoc spp. (D) counts in kefir samples produced with cow and buffalo milk using kefir grain and starter culture during storage. $\mathrm{K}=$ kefir, $\mathrm{G}=$ kefir grain, $\mathrm{S}=$ starter culture, $\mathrm{C}=$ cow milk, $\mathrm{B}=$ buffalo milk.

KG-C and KG-B. However, yeast counts of the KG-B sample increased to $5.48 \mathrm{log} \mathrm{cfu} / \mathrm{mL}$ at the end of storage period $(P<0.05)$. This discrepancy could have resulted from differences in minor components between milk types (Wszolek et al. 2001).

Although lactobacilli counts of the kefir samples produced from cow milk were found higher than buffalo milk kefir samples on d $1(P<0.05)$, milk type had no effect on lactobacilli counts of all kefir samples at the end of storage $(P>0.05$; Figure 1B). However, Han et al. (2007) stated that microorganisms can grow rapidly due to the high nutritional properties of buffalo milk.

Lactococci counts $(7.75 \log \mathrm{cfu} / \mathrm{mL}$ ) of KS-B were determined to be $\sim 1 \log \mathrm{cfu} / \mathrm{mL}$ higher than those of other kefir samples at the end of incubation $(P<0.05$; Figure 1C). Except for KG-C, lactococci counts in other kefir samples showed a significant increase $(P<0.05)$ until d 14; after d 14 of the storage period the lactococci populations of all kefir samples slightly decreased. This could be attributed to cell proteolysis due to a decrease in pH (Guzel-Seydim et al., 2005). Lactococci counts of the kefir samples made from buffalo milk using kefir grains were higher than the samples made from cow milk at the end of storage period $(P<0.05)$.

Leuconostoc spp. counts in the all kefirs were found to range from 4.65 to $5.9 \log \mathrm{cfu} / \mathrm{mL}$ at the end of incubation (Figure 1D); these findings were lower than other findings (García Fontán et al., 2006; Gronnevik et al., 2011). During the storage period, little change was noted in the Leuconostoc spp. counts in all kefir samples. Change in Leuconostoc spp. population was similar to that of lactococci during the storage period. Differences of Leuconostoc spp. counts between KS-C and KS-B samples (6.03 and $5.23 \log \mathrm{cfu} / \mathrm{mL}$, respec- 
tively) were only found to be significant at the end of the storage period $(P<0.05)$.

\section{Chemical Analysis}

The $\mathrm{pH}$ values of $\mathrm{KG}-\mathrm{C}, \mathrm{KG}-\mathrm{B}, \mathrm{KS}-\mathrm{C}$, and $\mathrm{KS}-\mathrm{B}$ were found to be 4.55, 4.26, 4.62 and 4.64, respectively, on d 1 (Figure 2A). Throughout storage, no significant difference between the mean $\mathrm{pH}$ values of the kefir samples was observed $(P>0.05)$. These results were in agreement with the findings of Guzel-Seydim et al. (2000a). Unlike the findings of Ahmad et al. (2008), although buffering capacity of buffalo milk was higher than that of cow milk, the $\mathrm{pH}$ values of kefir samples from buffalo and cow milk similarly decreased. Dilution of buffalo milk with water caused a decrease of buffering capacities of buffalo milk. The titratable acidity values of the kefir samples were found in the range of
0.64 to $0.76 \%$ at $d 1$ and titratable acidity did not show differences between kefir samples after the incubation and storage period $(P>0.05$; Figure $2 \mathrm{~B})$. This could be derived from high yeast contents that limit the multiplication of lactic acid bacteria and production of lactic and acetic acid (Collar, 1996). Total solid contents were similar and between 11.41 and $11.67 \%$ in all types of kefir samples because the cow and buffalo milk used for kefir production were standardized. Therefore, the microbiological and chemical difference of kefir samples during incubation and storage were associated with protein and minor compounds of milks.

Ethanol is responsible for the exotic, refreshing flavor and distinctive aroma of kefir, thus it is one of the most important quality factors in kefir. Ethanol content of the kefir samples showed significant differences due to production methods. Production with kefir grains provided higher $(P<0.05)$ ethanol content in kefir than
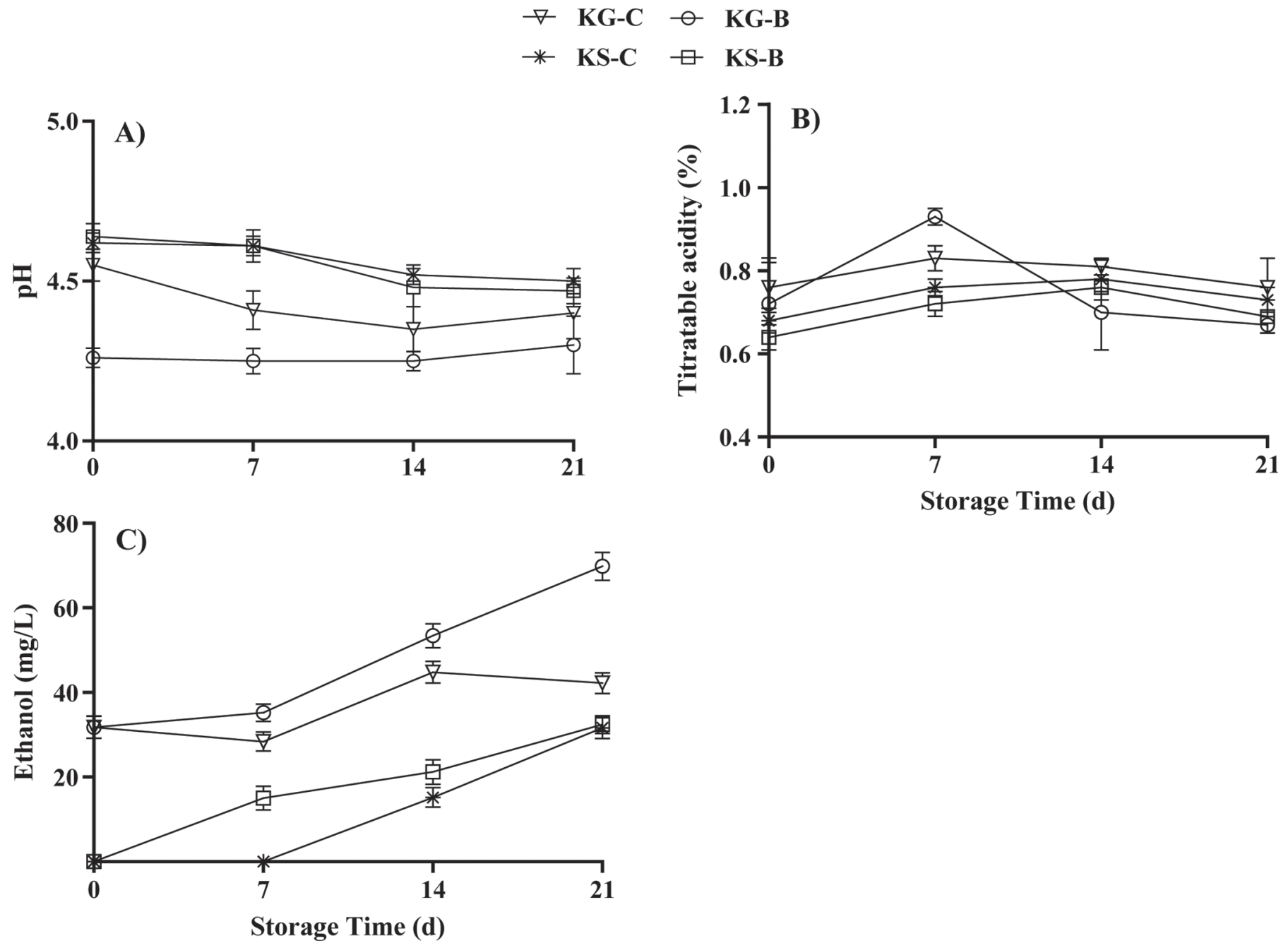

Figure 2. The change of $\mathrm{pH}(\mathrm{A})$, titratable acidity (B), and ethanol contents (C) in kefir samples produced with cow and buffalo milk using kefir grain and starter culture during storage. $\mathrm{K}=$ kefir, $\mathrm{G}=$ kefir grain, $\mathrm{S}=$ starter culture, $\mathrm{C}=$ cow milk, $\mathrm{B}=$ buffalo milk. 
production with kefir starter culture. This is a result of variation of yeast species (responsible for alcohol production) present in kefir samples (Guzel-Seydim et al., 2000a). Ethanol contents of KG-B and KG-C were not significantly different and ethanol levels were similar for both kefirs $(\sim 31.8 \mathrm{mg} / \mathrm{L})$, but ethanol was not detected in KS-B and KS-C on the first day (Figure 2c). During storage, a significant increase in the ethanol content of KG-B and KG-C was noted $(P<0.05)$. On d 21 , ethanol contents of KG-B and KG-C were 69.8 and $42.2 \mathrm{mg} / \mathrm{L}$, respectively. These values are within the range of values observed by Kök-Taş et al. (2013), who found that ethanol content of kefir samples ranged from 76.5 to $5.14 \mathrm{mg} / \mathrm{L}$ during storage. The higher ethanol content in KG-B compared with KG-C could be due to high yeast counts in KG-B $(P<0.05)$. Ethanol levels were detected in KS-B and KS-C samples on d 7 and 14 and significantly increased during the follow-up period of $7 \mathrm{~d}(P<0.05)$.

\section{Organic Acids}

The mean lactic acid levels of KG-C, KS-C, KG-B, and KS-B at d 1 were $7,905.96,8,618.73,6,826.81$, and $7,692.66 \mu \mathrm{g} / \mathrm{g}$, respectively (Figure 3A). Lactic acid contents of kefir samples made from cow milk did not vary significantly during storage $(P>0.05)$. This may be because lactobacilli of kefir samples made from cow and buffalo milk were similar during storage. However, lactic acid levels of KG-B and KS-B significantly increased during storage $(P<0.05)$ and reached to $9,207.97$ and $9,200.48 \mu \mathrm{g} / \mathrm{g}$, respectively, at $\mathrm{d} 21$. Guzel-Seydim et al. (2000a) found a statistically significant difference in lactic acid levels of the kefir samples
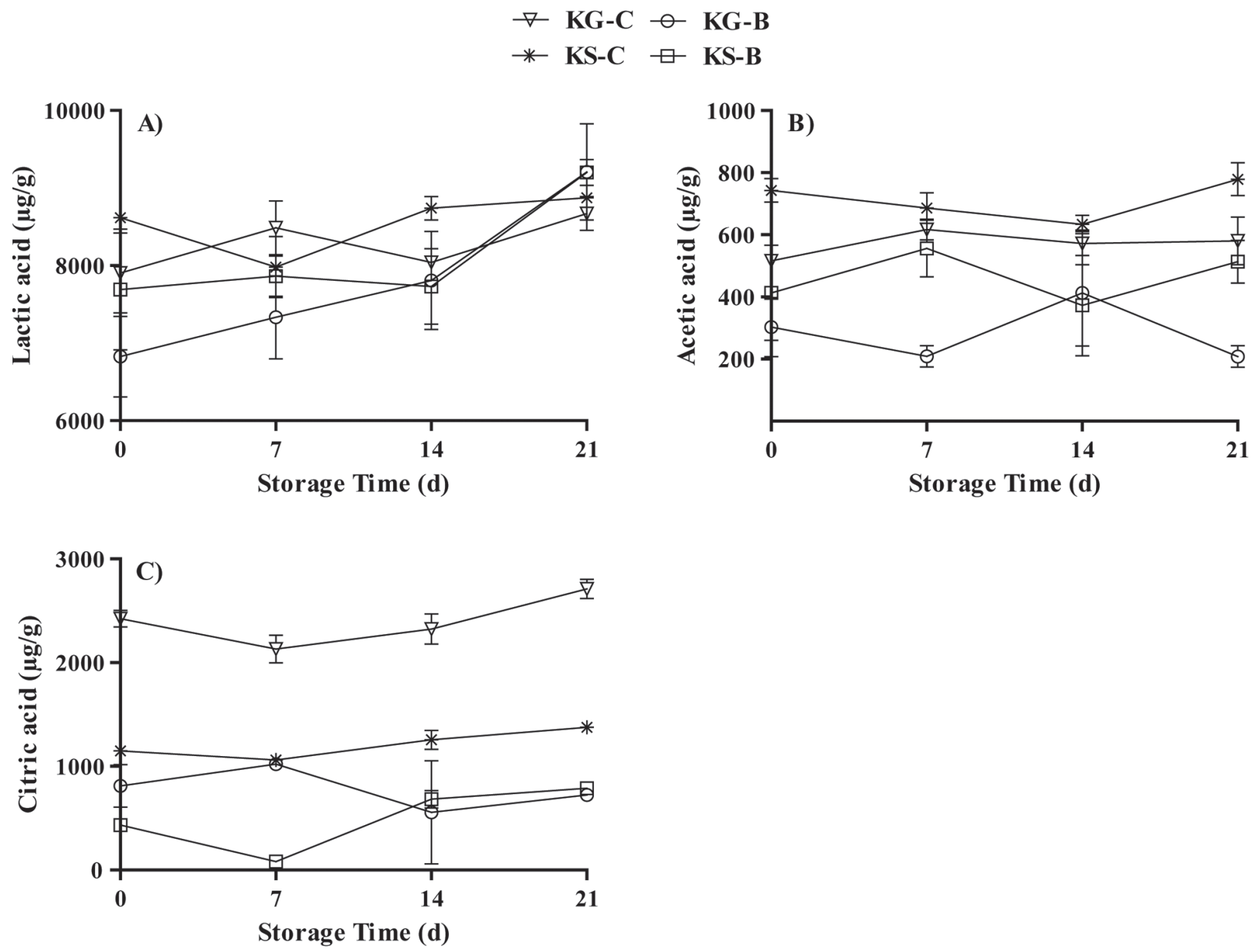

Figure 3. The change of lactic (A), acetic (B), and citric (C) acid concentrations in kefir samples produced with cow and buffalo milk using kefir grain and starter culture during storage. $\mathrm{K}=$ kefir, $\mathrm{G}=$ kefir grain, $\mathrm{S}=$ starter culture, $\mathrm{C}=$ cow milk, $\mathrm{B}=$ buffalo milk. 

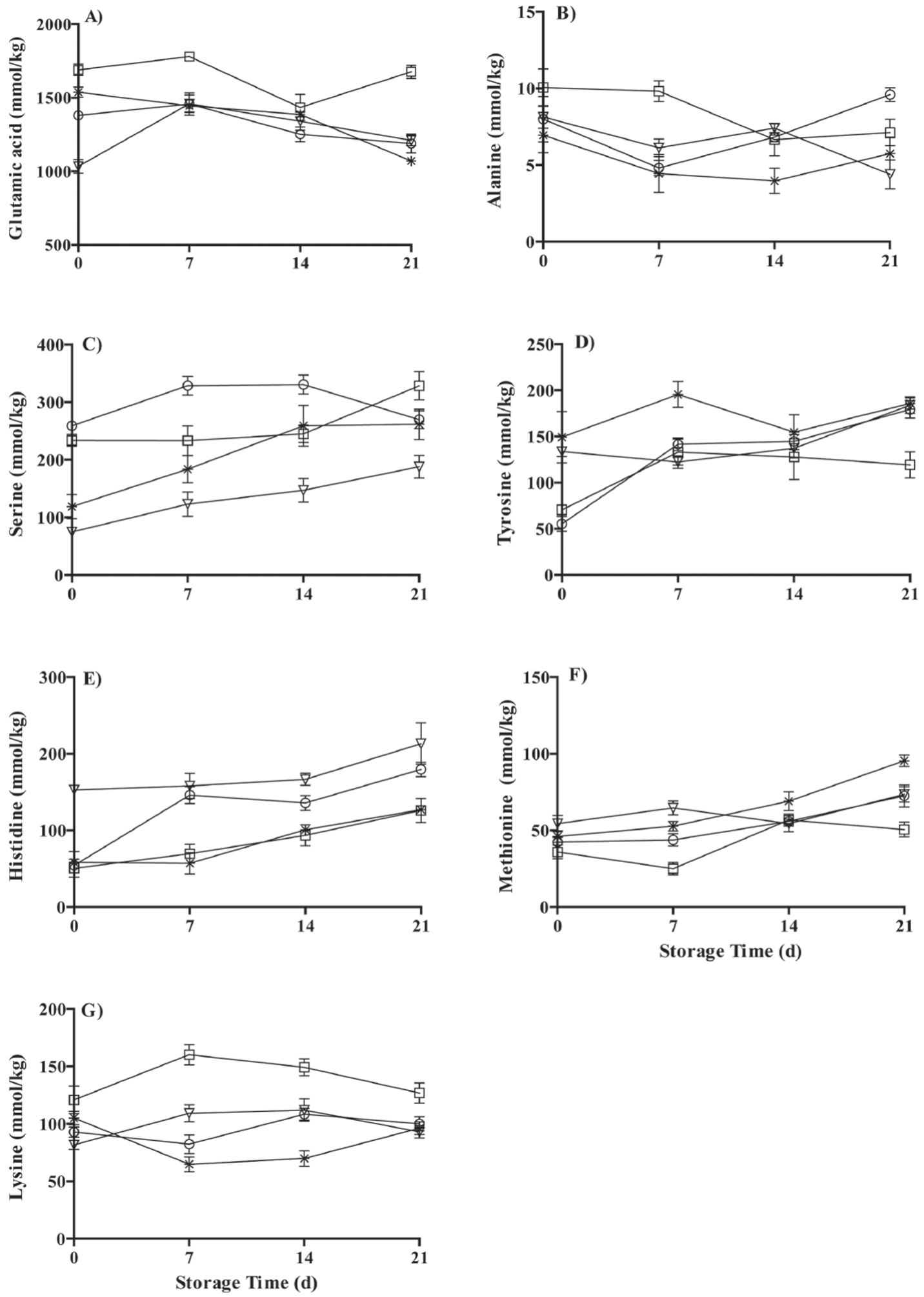

Figure 4. The change of glutamic acid (A), alanine (B), serine (C), tyrosine (D), histidine (E), methionine (F), and lysine (G) values in kefir samples produced with cow and buffalo milk using kefir grain and starter culture during storage. $\mathrm{K}=$ kefir, $\mathrm{G}=$ kefir grain, $\mathrm{S}=$ starter culture, $\mathrm{C}=$ cow milk, $\mathrm{B}=$ buffalo milk. 
produced with kefir grains between d $1(6,405 \mu \mathrm{g} / \mathrm{g})$ and $21(7,739 \mu \mathrm{g} / \mathrm{g})$. The mean acetic acid contents of KS-C and KG-C were found to be higher than those of KG-B and KS-B (Figure 3B). Cow milk caused higher acetic acid levels of kefir samples $(P<0.05)$. Similar results were observed in yogurt samples made from cow and buffalo milks (Erkaya and Sengül, 2011). Storage time had no significant effect on the acetic acid content of the each of the kefir samples, which indicates a lack of acetic acid production by acetic acid bacteria via oxidation of ethanol (Gronnevik et al., 2011). GuzelSeydim et al. (2000b) did not determine acetic acid in kefir samples depending on variation of the inoculation ratio and type of microorganisms in kefir grains. Citric acid concentration of the kefir samples at $d 1$ showed significant differences $(P<0.05)$ depending on milk type and production method (Figure $3 \mathrm{C}$ ). Citric acid levels of KG-C, KS-C, KG-B, and KS-B at d 1 were $2,453,1,147,811$, and $434 \mu \mathrm{g} / \mathrm{g}$, respectively, and were stable throughout the storage period. Guzel-Seydim et al., (2000b) also reported that citrate contents of kefir samples were not significantly different during the sampling period. Other organic acids, namely butyric and propionic acids, were not detected in the kefir samples during storage. Other studies also failed to find these organic acids in kefir samples (Guzel-Seydim et al., 2000a,b). This may have resulted from the variations in the ratio and types of microorganisms in kefir samples (Rea et al., 1996).

\section{AA}

The AA concentrations of the kefir samples made from cow and buffalo milk using kefir grain and starter culture are presented in Figure 4. Glutamic acid was detected as the major AA in the kefir samples. At the end of the incubation, higher concentrations of glutamic acid were found in KS-B and KG-B than in KS-C and KG-C $(P<0.05$; Figure 4A). During storage, glutamic acid concentrations increased from $1,034.2$ to $1,639.8$ $\mathrm{mmol} / \mathrm{kg}$ on $\mathrm{d} 1$ to $1,445.3$ to $1,780.1 \mathrm{mmol} / \mathrm{kg}$ on $\mathrm{d}$ 7, then decreased to $1,070.4$ to $1,434.4 \mathrm{mmol} / \mathrm{kg}$ on $\mathrm{d}$ $21(P<0.05)$. Our findings were in accordance with the results obtained by Gronnevik et al. (2011), who reported that the amount of glutamic acid continuously decreased during storage. The amounts of alanine were found to be $\sim 8$ to $10 \mathrm{mmol} / \mathrm{kg}$ after incubation for all kefir samples $(P>0.05$; Figure $4 \mathrm{~B})$; a slight decrease to 4.4 to $7.12 \mathrm{mmol} / \mathrm{kg}$ was detected during storage $(P>0.05)$. After incubation, serine concentrations were found in the range of 233.89 to $259.12 \mathrm{mmol} /$ $\mathrm{kg}$ for KG-B and KS-B and 74.86 to $118.89 \mathrm{mmol} / \mathrm{kg}$ for KG-C and KS-C (Figure 4C). Buffalo milk kefir samples contained higher serine than cow milk kefir samples at the end of incubation and storage $(P<$ 0.05 ). The buffalo milk kefir contained lower tyrosine, histidine, and methionine concentrations than cow milk kefir after incubation $(P<0.05$; Figure $4 \mathrm{D}, \mathrm{E}$, and $\mathrm{F})$. A significant increase of tyrosine and histidine levels was observed after d $21(P<0.05)$, but the changes of methionine levels were notable $(P>0.05)$. The highest lysine concentrations were found in KS-B (120.91 $\mathrm{mmol} / \mathrm{kg})$, followed by KS-C $(105.14 \mathrm{mmol} / \mathrm{kg})$, KG-B $(92.84 \mathrm{mmol} / \mathrm{kg})$, and KG-C $(81.67 \mathrm{mmol} / \mathrm{kg})$, as with glutamic acid after incubation $(P<0.05$; Figure $4 \mathrm{G})$. A slight change in lysine levels in all kefir samples was observed during storage, but it was not significant $(P$ $>0.05)$.

Generally, the AA concentrations of the kefir samples may have resulted from the combination of proteolytic activity, assimilation of peptides, and release of AA from the cells during incubation and storage. During storage, the change in glutamic acid may have been due to decarboxylation to g-aminobutyric acid (Gronnevik et al., 2011). Similarly, Fernández and Zúñiga (2006) explained that alanine concentration decreased during fermentation due to catabolism to pyruvate. Tyrosine, methionine, and serine concentrations increased during storage, probably due to proteolytic activity (Gronnevik et al., 2011).

\section{CONCLUSIONS}

In our study, kefir samples manufactured from cow and buffalo milk using kefir grains and starter culture had similar chemical properties except for ethanol. The type of milk used in kefir production affected microbiological characteristics, AA, and organic acid concentrations of the kefir samples. Changed of these properties in kefir samples were different depending on the types of culture during storage. The rapid yeast growth in buffalo milk kefir is very important due to the ethanol production in kefir. The highest ethanol content and yeast growth was detected in KG-B at the end of storage. Some probiotic yeast strains in kefir exhibited a beneficial effect on health, and ethanol provides the exotic, refreshing flavor and distinctive aroma of kefir. Thus, kefir production from buffalo milk using kefir grain may be preferred because of the flavor and aroma formed by yeast.

\section{REFERENCES}

Ahmad, S., I. Gaucher, F. Rousseau, E. Beaucher, M. Piot, J. F. Grongnet, and F. Gaucheron. 2008. Effects of acidification on physico-chemical characteristics of buffalo milk: A comparison with cow's milk. Food Chem. 106:11-17.

AOAC International. 1992. Official Methods of Analysis. AOAC International, Washington, DC.

Collar, C. 1996. Review: Biochemical and technological assessment of the metabolism of pure and mixed cultures of yeast and lactic 
acid bacteria in breadmaking applications. Food Sci. Technol. Int. 2:349-367.

de Moreno de LeBlanc, A., C. Matar, E. Farnworth, and G. Perdigon. 2006. Study of cytokines involved in the prevention of a murine experimental breast cancer by kefir. Cytokine 34:1-8.

Erbas, M. 2003. Changes in composition of wet tarhana during production and in different storage conditions. PhD Thesis. Akdeniz University, Science Education Institution, Antalya, Turkey.

Erkaya, T., and M. Sengül. 2011. Comparison of volatile compounds in yoghurts made from cows', buffaloes', ewes' and goats' milk. Int. J. Dairy Technol. 64:240-246.

Farnworth, E. R. 2006. Kefir-A complex probiotic. Food Sci. Tech. Bull. 2:1-17.

Fenelon, M. A., P. O'Connor, and T. P. Guinee. 2000. The effect of fat content on the microbiology and proteolysis in cheddar cheese during ripening. J. Dairy Sci. 83:2173-2183.

Fernández, M., and M. Zúñiga. 2006. Amino acid catabolic pathways of lactic acid bacteria. Crit. Rev. Microbiol. 32:155-183.

Fernandez-Garcia, E., and J. U. McGregor. 1994. Determination of organic acids during the fermentation and cold storage of yoghurt. J. Dairy Sci. 77:2934-2939.

García Fontán, M. C., S. Martínez, I. Franco, and J. Carballo. 2006. Microbiological and chemical changes during the manufacture of Kefir made from cows' milk, using a commercial starter culture. Int. Dairy J. 16:762-767.

Gronnevik, H., M. Falstad, and J. A. Narvhus. 2011. Microbiological and chemical properties of Norwegian kefir during storage. Int. Dairy J. 21:601-606.

Güven, A., A. Guven, and M. Gulmez. 2003. The effect of kefir on the activities of GSH-Px, GST, CAT, GSH and LPO levels in carbon tetrachloride-induced mice tissues. J. Vet. Med. B Infect. Dis. Vet. Public Health 50:412-416.

Guzel-Seydim, Z., A. Seydim, and A. Greene. 2000a. Organic acids and volatile flavor components evolved during refrigerated storage of kefir. J. Dairy Sci. 83:275-277.

Guzel-Seydim, Z. B., A. C. Seydim, and A. B. Bodine. 2000b. Determination of organic acids and volatile flavor substances in kefir during fermentatiton. J. Food Compos. Anal. 13:35-43.

Guzel-Seydim, Z. B., J. Twyffels, A. C. Seydim, and A. K. Greene. 2005. Turkish kefir and kefir grains: Microbial enumeration and electron microscopic observation. Int. J. Dairy Technol. 58:25-29.

Han, B. Z., Y. Meng, M. Li, Y. X. Yang, F. Z. Ren, Q. K. Zeng, and R. Nout. 2007. A survey on the microbiological and chemical composition of buffalo milk in China. Food Contr. 18:742-746.

Hertzler, S. R., and S. M. Clancy. 2003. Kefir improves lactose digestion and tolerance in adults with lactose maldigestion. J. Am. Diet. Assoc. 103:582-587.

Irigoyen, A., I. Arana, M. Castiella, P. Torre, and F. C. Ibáñez. 2005. Microbiological, physicochemical, and sensory characteristics of kefir during storage. Food Chem. 90:613-620.

Kök-Taş, T., A. C. Seydim, B. Özer, and Z. Guzel-Seydim. 2013. Effects of different fermentation parameters on quality characteristics of kefir. J. Dairy Sci. 96:780-789.
Laye, I., D. Karleskind, and C. V. Mor. 1993. Chemical, microbiological and sensory properties of plain nonfat yogurt. J. Food Sci. 58:1991-1995

Liu, J. R., M. J. Chen, and C. W. Lin. 2005. Antimutagenic and antioxidant properties of milk-kefir and soymilk-kefir. J. Agric. Food Chem. 53:2467-2474.

Lopitz-Otsoa, F., A. Rementeria, N. Elguezabal, and J. Garaizar. 2006. Kefir: A symbiotic yeasts-bacteria community with alleged healthy capabilities. Rev. Iberoam. Micol. 23:67-74.

Magra, T. I., K. A. Antoniou, and E. I. Psomas. 2012. Effect of milk fat, kefir grain inoculum and storage time on the flow properties and microbiological characteristics of kefir. J. Texture Stud 43:299-308.

Matsuu, M., K. Shichijo, K. Okaichi, C. Y. Wen, E. Fukuda, M. Nakashima, T. Nakayama, S. Shirahata, S. Tokumaru, and I. Sekine. 2003. The protective effect of fermented milk kefir on radiationinduced apoptosis in colonic crypt cells of rats. J. Radiat. Res. (Tokyo) 44:111-115.

McCue, P. P., and K. Shetty. 2005. Phenolic antioxidant mobilization during yogurt production from soymilk using Kefir cultures. Process Biochem. 40:1791-1797.

Oner, Z., A. G. Karahan, and M. L. Çakmakçı. 2010. Effects of different milk types and starter cultures on kefir. Food 35:177-182.

Otles, S., and O. Cagindi. 2003. Kefir: A probiotic dairy composition, nutritional and therapeutic aspects. Pak. J. Nutr. 2:54-59.

Paramas, A. M. G., J. A. G. Barez, C. C. Marcos, R. J. GarciaVillanova, and J. S. Sanchez. 2006. HPLC-fluorimetric method for analysis of amino acids in products of the hive (honey and beepollen). Food Chem. 95:148-156.

Petersson, H. E., A. Christiansson, and K. Ekelund. 1985. Making kefir without grains. Scand. J. Dairy Technol. Know How. 2:58-60.

Phill, L. 2005. Chai yoghurt from water buffalo milk. Gourmet Retail. $26: 101$.

Rea, M. C., T. Lennartsson, P. Dillon, F. D. Drinan, W. J. Reville, M. Heapes, and T. M. Cogan. 1996. Irish kefir-like grains: Their structure, microbial composition and fermentation kinetics. J. Appl. Microbiol. 81:83-94

Simova, E., D. Beshkova, A. Angelov, T. Hristozova, G. Frengova, and Z. Spasov. 2002. Lactic acid bacteria and yeasts in kefir grains and kefir made from them. J. Ind. Microbiol. Biotechnol. 28:1-6.

Temmerman, R., G. Huys, and J. Swings. 2004. Identification of lactic acid bacteria: culture-dependent and cultureindependent methods. Trends Food Sci. Technol. 15:348-359.

Witthuhn, R. C., T. Schoeman, and T. J. Britz. 2005. Characterization of the microbial population at different stages of kefir production and kefir grain mass cultivation. Int. Dairy J. 15:383-389.

Wszolek, M., A. Y. Tamime, D. D. Muir, and M. N. I. Barclay. 2001. Properties of kefir made in scotland and poland using bovine, caprine and ovine milk with different starter cultures. LWT-Food Sci Technol. 34:251-261. 